\title{
Physiological and Antioxidant
}

Parameters in Two Lycoris Species as Influenced by Water Deficit Stress

Sheng Xu

Institute of Botany, Jiangsu Province and Chinese Academy of Sciences, Nanjing 210014, China; and the Jiangsu Provincial Platform for Conservation and Utilization of Agricultural Germplasm, Nanjing 210014, China

Mingmin Jiang, Jiangyan Fu, and Lijian Liang

Institute of Botany, Jiangsu Province and Chinese Academy of Sciences, Nanjing 210014, China

\section{Bing Xia and Ren Wang ${ }^{1}$}

Institute of Botany, Jiangsu Province and Chinese Academy of Sciences, Nanjing 210014, China; and the Jiangsu Provincial Platform for Conservation and Utilization of Agricultural Germplasm, Nanjing 210014, China

Additional index words. Amaryllidaceae, antioxidant enzymes, lipid peroxidation, photosynthesis, pigments, reactive oxygen species, water deficit stress

\begin{abstract}
From a field experiment, the changes in morphophysiological characters and antioxidant enzyme activities were studied in two Lycoris species (Lycoris radiata and Lycoris aurea) subjected to 16 days of water deficit stress. With the increase of water deficit stress processing time, leaf relative water content (RWC), membrane stability index (MSI), net photosynthesis $\left(P_{n}\right)$, stomatal conductance $\left(g_{S}\right)$, transpiration rate $(E)$, and chlorophyll $(\mathrm{Chl})$ content decreased in both studied species. The water use efficiency (WUE) showed an opposite tendency between the two species under water deficit stress, where WUE of $L$. aurea decreased moderately and WUE of $L$. aurea increased somehow. Intercellular $\mathrm{CO}_{2}$ concentration $\left(C_{i}\right)$ in $L$. aurea and $L$. radiata decreased in respond to water deficit stress at early stages of stress treatment, then increased throughout the rest of the stress period, and reached levels higher than those in well-watered plants at the end of the treatment. In addition, there was a significant increment in soluble sugar content and proline accumulation under water deficit stress in both species, and $L$. radiata showed a much more accumulation. The activity of superoxide dismutase (SOD), guaiacol peroxidase (POD), and ascorbate peroxidase (APX) increased in both plants subjected to water deficit stress while declined as the stress time increased. In L. aurea, catalase (CAT) showed a sustained increment, but it responded later and after a transient increase declined again in $L$. radiata under water deficit stress. In conclusion, $L$. radiata was more tolerant to water deficit stress than $L$. aurea as evidenced by its relatively higher water status, higher levels of proline, soluble sugar and pigments, and stronger photoprotection. Moreover, relatively higher antioxidant enzyme activities and lower levels of thiobarbituric acid reactive substances (TBARS) in $L$. radiata were also associated with its better protection against water deficit stress-induced oxidative damage.
\end{abstract}

Water deficit is considered as a major environmental factor that influences various physiological and biochemical processes in plants (Tezara et al., 1999). Plants can exhibit either drought escape or drought resistance mechanisms, with resistance further classified

Received for publication 1 July 2015. Accepted for publication 17 Sept. 2015.

This work was supported by the National Natural Science Foundation (31301798; 31270339); Industry-academic Joint Technological Innovations Fund of Jiangsu Province (BY2014131); The Science Foundation of Institute of Botany, Jiangsu Province and Chinese Academy of Sciences (201201).

${ }^{1}$ Corresponding author. E-mail: jswangren@aliyun. com. into drought avoidance and drought tolerance. Drought is manifested primarily as osmotic stress, resulting in the disruption of homeostasis and ion distribution in the cell (Miller et al., 2010; Zhu, 2002), leading to increased accumulation of reactive oxygen species (ROS) such as superoxide $\left(\mathrm{O}_{2}^{-}\right)$, hydrogen peroxide $\left(\mathrm{H}_{2} \mathrm{O}_{2}\right)$, and the hydroxyl radical $(\cdot \mathrm{OH})$ in plants thus causing an oxidative stress (Miller et al., 2010; Zhu, 2002). Plants possess well-developed antioxidant metabolites, enzymes, and nonenzymes to a variable extent, which have the ability to detoxify ROS (Miller et al., 2010). Antioxidant metabolites and nonenzymatic antioxidant systems include ascorbate acid (AsA), carotenoids (Cars), reduced glutathione, $\beta$-carotenes, and $\alpha$-tocopherol. The antioxidant enzymes being the most efficient mechanisms against oxidative stress, which mainly include SOD; CAT; various PODs; glutathione-ascorbate (GSH) cycle enzymes such as APX, dehydroascorbate reductase, monodehydroascorbate reductase, and glutathione reductase (Farooq et al., 2009).

Lycoris Herb. is a genus of Amaryllidaceae composed of $\approx 20$ species and distributed in the moist warm temperate woodlands of eastern Asia such as China, Korea, and Japan (Hsu et al., 1994). L. radiata and $L$. aurea are two traditional groundcover plants and typical hysteranthous geophyte appearing in autumn. Their floral stems and flowers start growing from August to September, and the leaves grow from September to October. In the wild, $L$. radiata and $L$. aurea usually distribute in sheltered moist slops along streams in the mountains, edges of forests, paddy fields, and margins of plantations (Hsu et al., 1994). In addition, L. radiata seeds are often difficult to germinate and the seedlings take $\approx 10$ years to reach flowering size. Therefore, these plants have been usually produced by clonal propagation (Zhou et al., 2007).

Many studies of Lycoris have been performed on karyotypes analysis (Hsu et al., 1994; Zhou et al., 2007), morphology (He et al., 2011), medicine (Toriizuka et al., 2008), photosynthetic characteristics (Liu et al., 2012; Meng et al., 2008), molecular aspect (He et al., 2010), and characterization of transcriptome (Chang et al., 2011; Wang et al., 2013). Although it has been considered that Lycoris bulbs are very durable, tolerating the extremes of drought and waterlogging, as well as poor soil conditions, little information is available in the literature on the underlying mechanisms of water deficit stress-induced oxidative stress in Lycoris. Meanwhile, the comparisons among different Lycoris species under water deficit stress were poorly investigated. Here, the effects of water deficit stress on various aspects of physiological responses in two Lycoris species L. radiata and $L$. aurea were examined, with the aim of identifying factors that influence tolerance to water deficit stress in Lycoris species.

\section{Materials and Methods}

Plant material and growth conditions. The bulbs of two species (L. radiata and $L$. aurea) with the same or similar sizes (1.8$2.2 \mathrm{~cm}$ ) in diameter were planted and grown in a greenhouse at the research station of Institute of Botany, Jiangsu Province and Chinese Academy of Sciences (118 $83^{\prime}$ E, $\left.32^{\circ} 05^{\prime} \mathrm{N}\right)$, Nanjing, China. For the water deficit stress treatment, one seedling (with 2 3 leaves) was transferred into each plastic pot (15.0 $\mathrm{cm}$ top diameter and $14.5 \mathrm{~cm}$ deep), containing $1 \mathrm{~kg}$ of dry loamy soil of $25 \%$ sand, $25 \%$ organic matter, and $50 \%$ peat. Plants were placed in a chamber at a mean temperature $21.6 \pm 1.4{ }^{\circ} \mathrm{C}, 53.7 \% \pm 3.6 \%$ relative humidity, $14 / 10 \mathrm{~h}$ day/night rhythm with a photosynthetic photon flux $(P P F)$ density of $150-200 \mu \mathrm{mol} \cdot \mathrm{m}^{-2} \cdot \mathrm{s}^{-1}$. For water deficit stress, two watering regimes were set: 
$75 \%$ field capacity (FC) as the control group and $35 \% \mathrm{FC}$ as the stress group. $\mathrm{FC}$ was calculated according to: $\mathrm{FC}=(\mathrm{SW}-\mathrm{DW}) /$ DW, where SW was the weight of saturated soil and DW was the weight of dry soil. The pot masses were calculated for $75 \%$ and $35 \%$ FC according to the above equation. SW was determined after the pots were saturated for $24 \mathrm{~h}$ (the gravimetric water was allowed to drain). Then the soil was dried and DW was determined (Sun et al., 2013). During the experiment, the evapotranspiration loss was supplemented gravimetrically by weighing the pots every other day. Pots were randomly and periodically rotated to minimize the effect of environmental heterogeneity. At the indicated time of experiment (lasting for $16 \mathrm{~d}$ ), three randomly selected seedlings from each treatment per species were harvested, and the leaves in the middle part of the plants were sampled to make physiological assays.

Measurement of leaf $R W C$. Leaf RWC was estimated gravimetrically according to the method of Shrestha et al. (2003). Briefly, three leaf discs $\left(1 \mathrm{~cm}^{2}\right)$ per plant were cut and weighed immediately to determine their fresh weight $(\mathrm{FW})$. After being immersed in distilled water for $8 \mathrm{~h}$ under low irradiance, the leaves were reweighed as turgid weight (TW), and then dried at $70{ }^{\circ} \mathrm{C}$ for $48 \mathrm{~h}$ to obtain their dry weight (DW). RWC was calculated according to: RWC $(\%)=(\mathrm{FW}-$ $\mathrm{DW}) /(\mathrm{TW}-\mathrm{DW}) \times 100$.

Photosynthetic traits measurements. $\mathrm{P}_{\mathrm{n}}$, $g_{\mathrm{S}}, C_{\mathrm{i}}$, and $E$ were measured with a Li-6400 portable photosynthesis system analyzer (LICOR, Lincoln, NE) under $25 \pm 0.3{ }^{\circ} \mathrm{C}, 1500$ $\mu \mathrm{mol} \cdot \mathrm{m}^{-2} \cdot \mathrm{s}^{-1}$ intensity of radiation, and $380 \pm$ $2.83 \mu \mathrm{mol} \cdot \mathrm{mol}^{-1} \mathrm{CO}_{2}$ concentration. Water use efficiency was calculated as the ratio of $\mathrm{P}_{\mathrm{n}} / E$. The photosynthetic light response curves were constructed after $16 \mathrm{~d}$ of water deficit stress treatment. Photosynthesis measurements were made between 9:00 AM and 11:00 AM on fully expanded leaves from each plant with a leaf temperature of $25{ }^{\circ} \mathrm{C}$ and a relative humidity of $70 \%$. Leaves were exposed to a series of $P P F$ density (PPFD) values: $2000,1600,1300,1000,800,600$, $400,200,100,50,20$, and $0 \mu \mathrm{mol} \cdot \mathrm{m}^{-2} \cdot \mathrm{s}^{-1}$.

Leaf pigments content. Total photosynthetic pigments were extracted with $95 \%$ ethanol. Fresh leaf tissue $(0.1 \mathrm{~g})$ was placed in a test tube containing $10 \mathrm{~mL} \mathrm{95 \%} \mathrm{ethanol}$ and left in the dark for $72 \mathrm{~h}$. The absorbance of the extract was measured spectrophotometrically at 480, 665, $649 \mathrm{~nm}$, and the turbidity of the extract was checked at $750 \mathrm{~nm}$ to be sure that it was always less than 0.01. The amounts of Chl and Car were calculated using the equations as described by Lichtenthaler (1987).

Determination of soluble sugar content. Leaves $(0.5 \mathrm{~g}, \mathrm{FW})$ were ground in a mortar and pestle. Then $1 \mathrm{~mL}$ of $80 \%$ ethanol was added, and the mixture was filtered. The filtrates were recovered, and the residues were washed again with $80 \%$ ethanol and filtered. Both filtrates were mixed, and $3 \mathrm{~mL}$ of distilled water was added. The extract was centrifuged at $12,000 \mathrm{~g}_{\mathrm{n}}$ for $15 \mathrm{~min}$, and $1 \mathrm{~mL}$ of supernatant was collected. Soluble sugar concentration was determined by the sulfuric acid anthrone method (Yemm and Willis, 1954).

Proline content. $0.5 \mathrm{~g}$ of FW leaves was extracted for free proline content measurements according to Bates et al. (1973). The reaction mixture consisted of $2 \mathrm{~mL}$ of leaf tissue extract, $2 \mathrm{~mL}$ of acid ninhydrin, and $2 \mathrm{~mL}$ of glacial acetic acid, and was boiled at $100{ }^{\circ} \mathrm{C}$ for $1 \mathrm{~h}$. The reaction was then terminated in an ice bath, and the reaction mixture was extracted with $4 \mathrm{~mL}$ of toluene. The absorbance was read at $520 \mathrm{~nm}$, and the free proline content was expressed on $\mathrm{FW}$ basis (micrograms per gram).

Measurements of TBARS content and $M S I$. Lipid peroxidation was estimated by measuring the concentrations of TBARS as described by Hodges et al. (1999). $0.5 \mathrm{~g}$ of leaves was homogenized in $5 \mathrm{~mL}$ of $80 \%$ $(\mathrm{v} / \mathrm{v})$ ethanol on ice. Following centrifugation at $10,000 g_{\mathrm{n}}$ for $20 \mathrm{~min}$ at $4{ }^{\circ} \mathrm{C}$, the supernatant $(2 \mathrm{~mL})$ was mixed with $2 \mathrm{~mL}$ of $20 \%$ $(\mathrm{w} / \mathrm{v})$ trichloroacetic acid containing $0.65 \%$ (w/v) thiobarbituric acid. The mixture was incubated at $95{ }^{\circ} \mathrm{C}$ for $30 \mathrm{~min}$ and then immediately cooled in an ice bath. After centrifugation at $10,000 g_{\mathrm{n}}$ for $10 \mathrm{~min}$, the absorbance of the supernatant was measured at $532 \mathrm{~nm}$, subtracting the value for nonspecific absorption at $600 \mathrm{~nm}$. The TBARS concentration was calculated from the extinction coefficient $155 \mathrm{~mm}^{-1} \cdot \mathrm{cm}^{-1}$.

For membrane stability analysis, leaf samples $(0.5 \mathrm{~g})$ were cut into discs of uniform size and placed in test tube containing $20 \mathrm{~mL}$ of distilled water at $40{ }^{\circ} \mathrm{C}$ for $30 \mathrm{~min}$. After the end of this period, their electrical conductivity (EC) was recorded by conductivity meter $(\mathrm{C} 1)$. Subsequently, the same samples were placed on boiling water bath $\left(100^{\circ} \mathrm{C}\right)$ for $10 \mathrm{~min}$ and their EC was recorded $(\mathrm{C} 2)$. The membrane stability index was calculated as $\operatorname{MSI}(\%)=[1-(\mathrm{C} 1 / \mathrm{C} 2)] \times 100($ Deshmukh et al., 1991).

Antioxidant enzymes assays. $0.5 \mathrm{~g}$ of leaves was homogenized in $10 \mathrm{~mL}$ of $50 \mathrm{~mm}$ potassium phosphate buffer ( $\mathrm{pH} 7.0$ ) containing $1 \mathrm{~mm}$ ethylenediaminetetraacetic acid and $1 \%$ polyvinylpyrrolidone for CAT (EC 1.11.1.6), POD (EC 1.11.1.7), and SOD (EC 1.15.1.1) assay, or combination with the addition of $1 \mathrm{~mm}$ ascorbic acid (ASC) in the case of APX (EC 1.11.1.11) assay. The homogenate was centrifuged at 12,000 $g_{n}$ for $20 \mathrm{~min}$ at $4{ }^{\circ} \mathrm{C}$, and the supernatant was used as the crude enzyme extract. Protein was determined by the method of Bradford (1976) with bovine serum albumin as the standard. CAT activity was spectrophotometrically measured by monitoring the consumption of $\mathrm{H}_{2} \mathrm{O}_{2}\left(\varepsilon=39.4 \mathrm{~mm}^{-1} \cdot \mathrm{cm}^{-1}\right)$ at $240 \mathrm{~nm}$ for at least 3 min (Zhang and Kirkham, 1996). POD activity was performed by measuring the oxidation of guaiacol $\left(\varepsilon=26.6 \mathrm{~mm}^{-1} \cdot \mathrm{cm}^{-1}\right)$ at $470 \mathrm{~nm}$ within 2 min (linear phase) after the addition of $\mathrm{H}_{2} \mathrm{O}_{2}$ (Herzog and Fahimi, 1973). SOD activity was measured on the basis of its ability to reduce nitroblue tetrazolium (NBT) by $\mathrm{O}_{2}^{-}$anion generated by the riboflavin system under illumination. One unit of SOD (U) was defined as the amount of crude enzyme extract required to inhibit the reduction rate of NBT by $50 \%$ (Beauchamp and Fridovich, 1971). APX activity was measured by monitoring the decrease in absorbance at $290 \mathrm{~nm}$ as ASC was oxidized $(\varepsilon=2.8$ $\mathrm{mm}^{-1} \cdot \mathrm{cm}^{-1}$ ) for at least $1 \mathrm{~min}$ in $3 \mathrm{~mL}$ reaction mixture, as described by Nakano and Asada (1981). Each result was the mean of three replications.

Statistical analysis. Where indicated, results were expressed as the mean \pm SE of three independent replicates. Analyses were performed with the software Statistical Package for the Social Science (SPSS) version 11.0 (SPSS Inc., Chicago, IL). For statistical analysis, the Duncan's multiple range test $(P<$ $0.05)$ was chosen where appropriately. Significant intervariable correlations were determined with a Pearson's coefficient test at $P<0.05$ or $P<0.01$.

\section{Results}

Leaf $R W C$. Compared with the treatment of day 0 , the leaf RWC reduced slightly but not significantly in both $L$. radiata and $L$. aurea under unstressed condition. There were also no significant changes in RWC between $L$. radiata and $L$. aurea (Fig. 1). With the water deficit stress, the obvious decreases of RWC were observed in both species when compared with their nonstressed controls at the different water deficit stress time. For example, after $4 \mathrm{~d}$ of water deficit stress, $L$. radiata leaves showed a slight decrease in the RWC from $82.75 \%$ to $77.75 \%$, while a significant decrease from $85.53 \%$ to $75.09 \%$ in RWC of $L$. aurea was observed $(P<0.05)$. The longer the water deficit stress was imposed, the more RWC content declined. After $16 \mathrm{~d}$ of further water deficit stress, the RWC of L. radiata and of L. aurea declined with a $16.04 \%$ and $24.65 \%$ decrease of the initial values (day 0 ), respectively (Fig. 1)

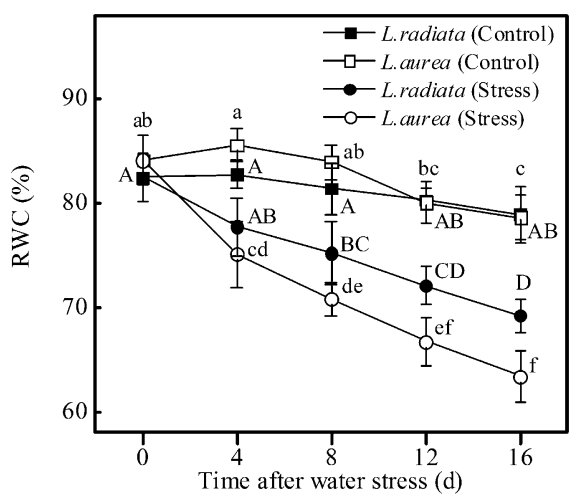

Fig. 1. Changes of leaf relative water content (RWC) in Lycoris radiata and Lycoris aurea subjected to water deficit stress for the indicated time. Data are the means of three replicates with SDs shown by vertical bars. Data of each parameter within each species followed by the same letter are not significantly different $(P<0.05)$. 
Photosynthetic traits. Gas exchange measurements were conducted under defined conditions in the chamber for the experimental period. In the unstressed condition, $\mathrm{P}_{\mathrm{n}}$ was higher in L. radiata than in L. aurea (Fig. 2A). Under water deficit stress, a gradual reduction in $P_{n}$ was observed in the two species (Fig. 2A). The difference in the reduction in $\mathrm{P}_{\mathrm{n}}$ between $L$. aurea and $L$. radiata was much more apparent under water deficit stress. For example, the extent of reduction in $\mathrm{P}_{\mathrm{n}}$ after $4 \mathrm{~d}$ of water deficit stress was lower in L. radiata (7.6\%) and more pronounced in $L$. aurea $(26.2 \%)$. Further, $16 \mathrm{~d}$ withholding water caused $19.6 \%$ and $56.9 \%$ decrease in $\mathrm{P}_{\mathrm{n}}$, relatively to control value in $L$. aurea and $L$. radiata, respectively (Fig. 2A). Besides, water deficit stress strongly inhibited $E$ (Fig. 2B). In both $L$. radiata and $L$. aurea, $E$ was reduced to a similar extent by water deficit stress. For instance, after $4 \mathrm{~d}$ of treatment, it caused $16.60 \%$ and $15.43 \%$ reduction for $L$. radiata and $L$. aurea, respectively, compared with their unstressed controls (Fig. 2B). As water deficit stress treatment time increased, $E$ continuously decreased up to day 16 (Fig. 2B).

Under unstressed condition, $g_{\mathrm{S}}$ was higher in $L$. aurea than in L. radiata at each time point, whereas the $g_{\mathrm{S}}$ of both $L$. radiata and $L$. aurea was reduced to a similar extent by water deficit stress (Fig. 2C). Similar to $E, C_{\mathrm{i}}$ of $L$. aurea was slightly higher than $L$. radiata under the unstressed conditions at each time point (Fig. 2D). After water deficit stress, the tendency of $C_{\mathrm{i}}$ in the two species decreased first and then increased, but obvious differences existed. For example, the minimum $C_{\mathrm{i}}$ of $L$. aurea was observed at day 4 with water deficit stress (with a decrease of $13.3 \%$ compared with its unstressed sample), whereas the minimum of $L$. radiata appeared at day 8 (with a decrease of $20.6 \%$ compared with its unstressed samples). After $16 \mathrm{~d}$ of treatment, $C_{\mathrm{i}}$ of the two species increased greatly than their corresponding unstressed controls (with an increment of $11.8 \%$ in $L$. aurea and an increment of $15.9 \%$ in $L$. radiata). It is worthy of being noticed that the WUE in leaves of $L$. aurea showed an opposite tendency compared with WUE in L. radiata under water deficit stress (Fig. 2E). Under unstressed condition, WUE of $L$. radiata was higher than $L$. aurea at each time point, which is similar to the changes of $\mathrm{P}_{\mathrm{n}}$ (Fig. 2E). During the treatment period, $L$. aurea showed a moderately decreased trend, while WUE of L. aurea increased somehow (Fig. 2E). Additionally, Changes in $g_{\mathrm{S}}$ were well correlated with $\mathrm{P}_{\mathrm{n}}$ values $(r=0.830, P<$ 0.01 and $r=0.947, P<0.01)$ only in water deficit-stressed Lycoris species (Fig. 3A). Similar results were also observed in the correlation between $g_{\mathrm{S}}$ and $E$ (Fig. 3B).

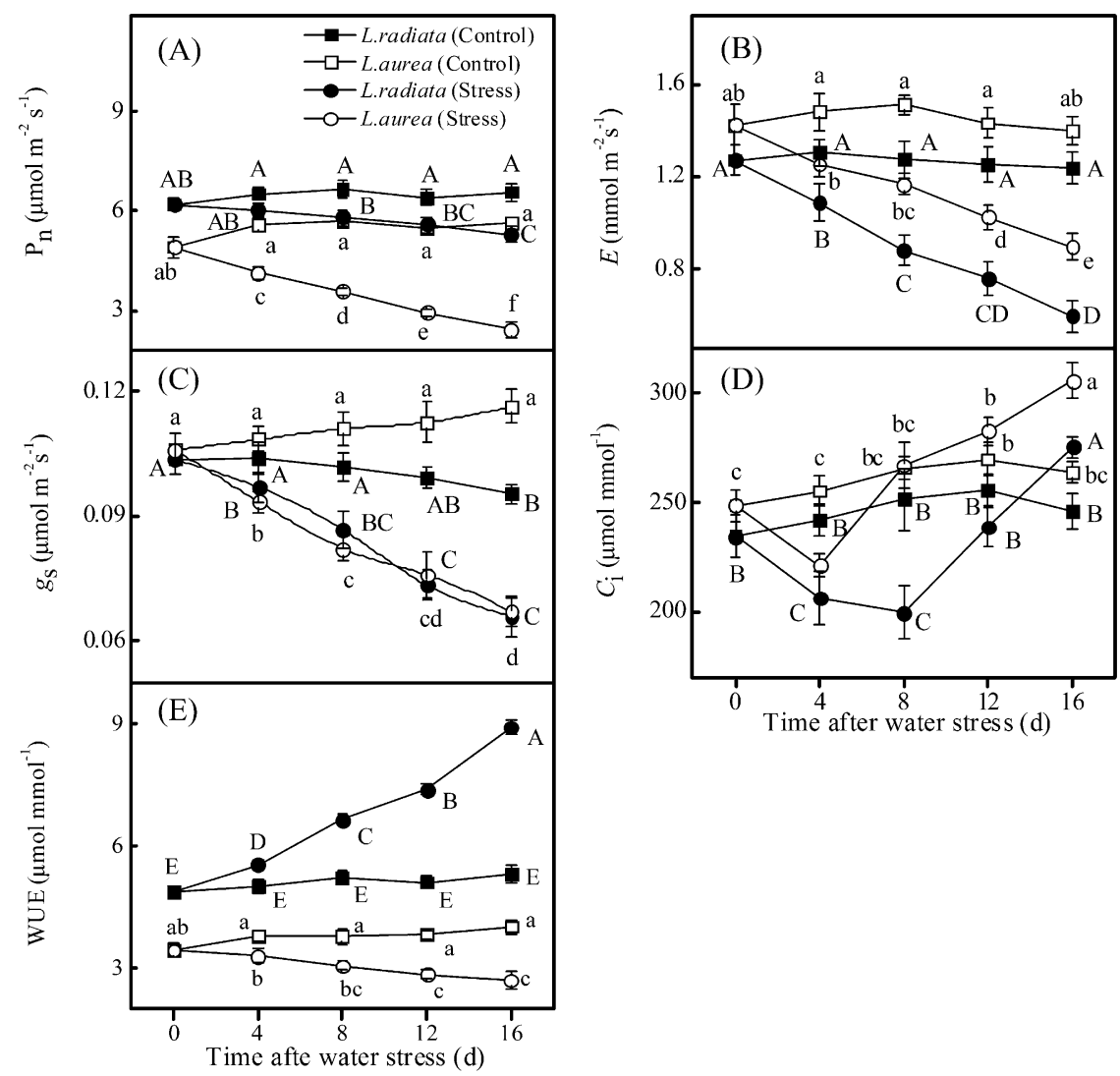

Fig. 2. (A) Net photosynthetic $\left(\mathrm{P}_{\mathrm{n}}\right),(\mathbf{B})$ transpiration rate $(E),(\mathbf{C})$ stomatal conductance $\left(g_{\mathrm{S}}\right)$, (D) intercellular $\mathrm{CO}_{2}$ concentration $\left(C_{\mathrm{i}}\right.$,), and (E) water use efficiency (WUE) changes in Lycoris radiata and Lycoris aurea as influenced by water deficit stress. Data are the means of three replicates with SDS shown by vertical bars. Data of each parameter within each species followed by the same letter are not significantly different $(P<0.05)$.
Photosynthetic light response curves showed that $\mathrm{P}_{\mathrm{n}}$ increased with the increment of PPFD and the patterns of the light response curves were similar between two species under both stressed and unstressed conditions (Fig. 4). Under water deficit stress, both the species recorded lower light saturation point (LSP) than those grown under unstressed condition (Table 1). The LSP for L. radiata under unstressed condition was found to be the highest. In contrast to LSP, it was observed that the light compensation point was higher under water deficit stress compared with the unstressed condition where there were no significant differences between the two species. In addition, the apparent

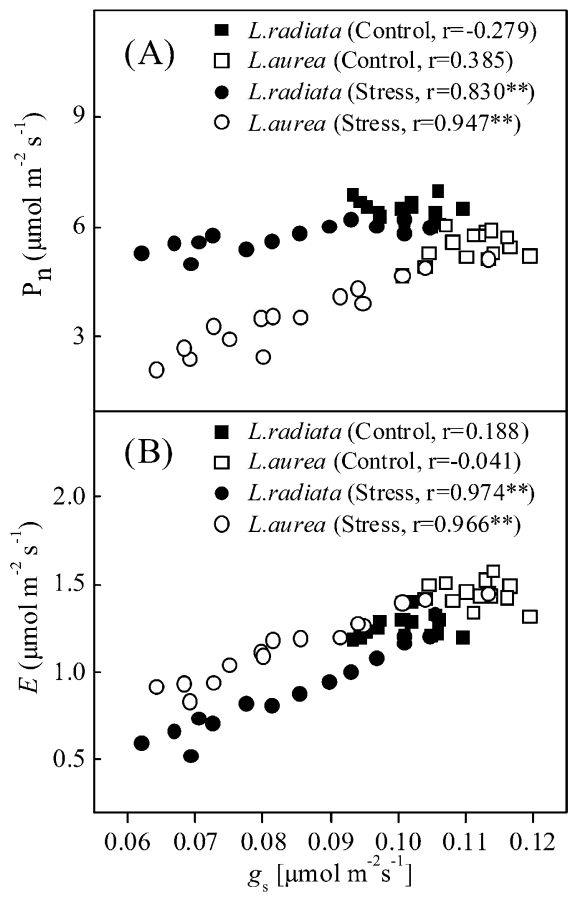

Fig. 3. Correlations between (A) stomatal conductance $\left(g_{\mathrm{S}}\right)$ and net photosynthesis $\left(\mathrm{P}_{\mathrm{n}}\right)$ and between $(\mathbf{B}) g_{\mathrm{S}}$ and transpiration rate $(E)$ in Lycoris radiata and Lycoris aurea under water deficit stress. ${ }^{* *}$ represents significance at the $1 \%$ levels of probability.

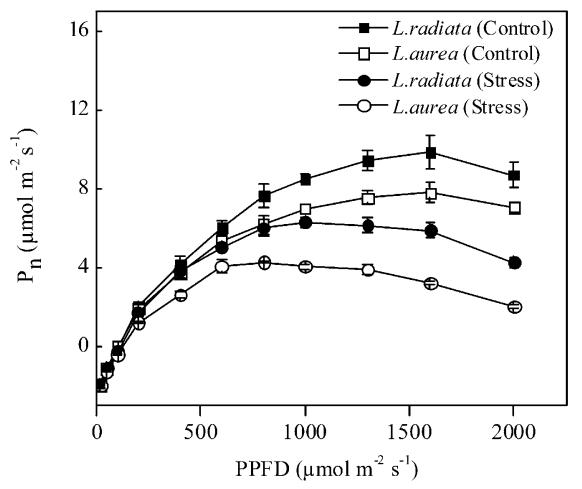

Fig. 4. Effect of water deficit stress on the light response curve of the two Lycoris species. Data are the means of three replicates with SDS shown by vertical bars.

HortScience Vol. 50(11) November 2015 
Table 1. Effect of water deficit stress on light compensation point (LCP), light saturation point (LSP), and apparent quantum yield (AQY) in Lycoris radiata and Lycoris aurea.

\begin{tabular}{|c|c|c|c|c|}
\hline \multirow{2}{*}{$\begin{array}{l}\text { Species } \\
\text { L. radiata }\end{array}$} & Treatment & $\operatorname{LSP}\left(\mu \mathrm{mol} \cdot \mathrm{m}^{-2} \cdot \mathrm{s}^{-1}\right)$ & $\mathrm{LCP}\left(\mu \mathrm{mol} \cdot \mathrm{m}^{-2} \cdot \mathrm{s}^{-1}\right)$ & $\mathrm{AQY}\left(\mu \mathrm{mol} \cdot \mathrm{m}^{-2} \cdot \mathrm{s}^{-1}\right)$ \\
\hline & Stress & $1,247.25 \pm 84.85 \mathrm{ab}(87.0 \%)$ & $125.04 \pm 7.78 \mathrm{ab}(112.3 \%)$ & $0.0217 \pm 0.0017 \mathrm{ab}(87.1 \%)$ \\
\hline \multirow[t]{2}{*}{ L. aurea } & Control & $1,402.82 \pm 98.99 \mathrm{ab}(100 \%)$ & $106.86 \pm 6.90 \mathrm{~b}(100 \%)$ & $0.0222 \pm 0.0018 \mathrm{ab}(100 \%)$ \\
\hline & Stress & $1,142.14 \pm 76.37 \mathrm{~b}(81.4 \%)$ & $131.46 \pm 7.07 \mathrm{a}(123.0 \%)$ & $0.0182 \pm 0.0014 \mathrm{~b}(82.0 \%)$ \\
\hline
\end{tabular}

${ }^{\mathrm{z}}$ Data in parentheses are relative values of the control.

The values represent the averages $( \pm \mathrm{SE})$ of three independent replicates followed by different letters within columns are significantly different at $P<0.05$, according to Duncan's multiple range test.

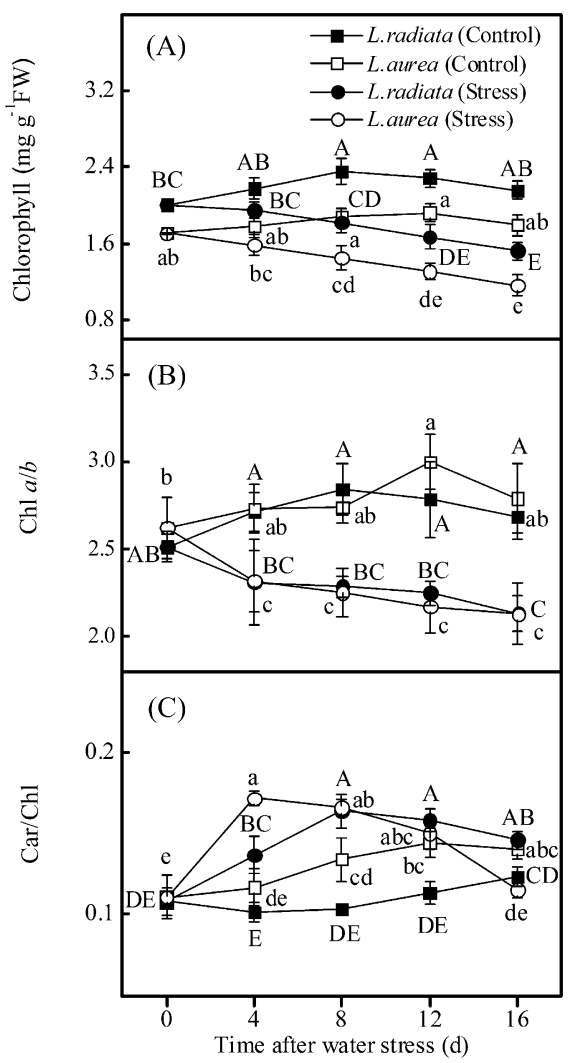

Fig. 5. (A) Chlorophyll $a$, (B) chlorophyll $b$, and (C) carotenoid content changes in Lycoris radiata and Lycoris aurea as influenced by water deficit stress. Data are the means of three replicates with SDs shown by vertical bars. Data of each parameter within each species followed by the same letter are not significantly different $(P<0.05)$.

quantum yield (AQY) measured in the stress condition for the two species displayed lower values than those from the unstressed controls, and $L$. aurea under water deficit stress exhibits the lowest AQY (Table 1).

Pigments. The $\mathrm{Chl}$ contents were reduced in both species under water deficit stress (Fig. 5A). Under unstressed condition, the values of $\mathrm{Chl}$ were higher in $L$. radiata than in L. aurea (Fig. 5A). After $16 \mathrm{~d}$ of water deficit stress, the Chl contents decreased $33.95 \%$ and $39.95 \%$ in $L$. radiata and $L$. aurea, respectively, when compared with the unstressed sample. Meanwhile, water deficit stress also decreased the ratio of $\mathrm{Chl}$ a to $\mathrm{Chl} b$ in both $L$. radiata and L. aurea (Fig. 5B). However, there were no significant differences on the ratio of $\mathrm{Chl}$ a to $\mathrm{Chl} b$ between $L$. radiata and $L$. aurea under water deficit

Table 2. Soluble sugar and proline content in the two Lycoris species subjected to water deficit stress for the indicated time.

\begin{tabular}{llcl}
\hline Species & Treatment & Soluble sugar content $\left(\mathrm{mg} \cdot \mathrm{g}^{-1} \mathrm{FW}\right)$ & Proline content $\left(\mu \mathrm{g} \cdot \mathrm{g}^{-1} \mathrm{FW}\right)$ \\
\hline L. radiata & Day 0 & $10.89 \pm 0.33 \mathrm{c}(100 \%)^{2}$ & $19.73 \pm 1.73 \mathrm{c}(100 \%)$ \\
& Day 4 control & $10.80 \pm 0.44 \mathrm{c}(99.2 \%)$ & $19.04 \pm 1.82 \mathrm{c}(96.5 \%)$ \\
& Day 4 stress & $12.84 \pm 0.75 \mathrm{~b}(117.9 \%)$ & $24.76 \pm 2.04 \mathrm{~b}(125.5 \%)$ \\
& Day 16 control & $11.93 \pm 0.60 \mathrm{bc}(109.6 \%)$ & $21.01 \pm 1.80 \mathrm{bc}(106.5 \%)$ \\
& Day 16 stress & $16.34 \pm 0.6 \mathrm{a}(150.0 \%)$ & $49.25 \pm 2.50 \mathrm{a}(249.6 \%)$ \\
L. aurea & Day 0 & $11.31 \pm 0.65 \mathrm{c}(100 \%)$ & $18.15 \pm 1.64 \mathrm{c}(100 \%)$ \\
& Day 4 control & $11.36 \pm 0.40 \mathrm{c}(100.4 \%)$ & $17.82 \pm 1.50 \mathrm{c}(98.2 \%)$ \\
& Day 4 stress & $12.79 \pm 0.65 \mathrm{~b}(113.1 \%)$ & $21.08 \pm 1.58 \mathrm{bc}(116.1 \%)$ \\
& Day 16 control & $12.05 \pm 0.47 \mathrm{bc}(106.5 \%)$ & $19.85 \pm 1.55 \mathrm{c}(109.4 \%)$ \\
& Day 16 stress & $13.15 \pm 0.51 \mathrm{~b}(116.3 \%)$ & $24.22 \pm 0.48 \mathrm{~b}(133.4 \%)$ \\
\hline
\end{tabular}

${ }^{\mathrm{z}}$ Data in parentheses are relative values of the control.

The values represent the averages $( \pm \mathrm{SE})$ of three independent replicates followed by different letters within columns are significantly different at $P<0.05$, according to Duncan's multiple range test.

stress. In addition, under unstressed condition, $L$. radiata and $L$. aurea exhibited a slight but not significant increase on the ratio of Car to Chl (Fig. 5C). The peak of the ratio of Car to Chl in L. radiata was observed after $8 \mathrm{~d}$ treatment of water deficit stress, with a $16.9 \%$ increment when compared with the day 0 . The maximum of $L$. aurea on the ratio of Car to Chl appeared at day 4.

Changes of soluble sugar and proline content under water deficit stress. The soluble sugar contents were increased in both species under water deficit stress (Table 2). Water deficit stress-induced soluble sugar increased by $\approx 17.9 \%$ and $50.0 \%$ in $L$. radiata after 4 and $8 \mathrm{~d}$ of water deficit stress, respectively, when compared with day 0 , whereas soluble sugar content in $L$. aurea only increased by $\approx 13.1 \%$ and $16.3 \%(P<$ 0.05 , Table 2). Similar to soluble sugar, the proline content in both species also showed increased tendency under water deficit stress (Table 2). The proline contents of $L$. radiata plants were higher than those of $L$. aurea at each time of water deficit stress treatment. In particular, after $16 \mathrm{~d}$ of water deficit stress, the proline content of $L$. radiata was $\approx 2$-fold that of L. aurea.

Lipid peroxidation and MSI. In Fig. 5A, TBARS contents of L. radiata and L. aurea seedlings subjected to water deficit stress for $16 \mathrm{~d}$ were shown. After $16 \mathrm{~d}$ treatment of water deficit stress, it was increased by $\approx 26.46 \%$ in $L$. radiata and $63.86 \%$ in $L$. aurea when compared with their unstressed controls. In addition, MSI significantly decreased in both $L$. radiata and $L$. aurea under water deficit stress (Fig. 6B). There were no significant differences between $L$. radiata and L. aurea in MSI under unstressed condition. But there was a small but significant difference between the two at $12 \mathrm{~d}$ of water deficit stress, with the $L$. aurea having slightly lower levels than L. radiata.

Antioxidant enzymes. Figure 7 showed the activity changes of SOD, POD, CAT, and APX in the two species. Activity of SOD in the two species showed a similar trend, but the SOD activity of $L$. radiata was greater than that of $L$. aurea under both unstressed and stressed conditions. SOD activity of $L$. radiata peaked after $12 \mathrm{~d}$ of water deficit stress treatment, up to $206.08 \mathrm{U} \cdot \mathrm{g}^{-1} \mathrm{FW}$, and the maximum of $L$. aurea appeared at day 8 , up to $139.25 \mathrm{U} \cdot \mathrm{g}^{-1} \mathrm{FW}$, which were $167 \%$ and $143 \%$ as compared with their unstressed controls, respectively. Meanwhile, the highest rate of increase in SOD activity was still found in $L$. radiata on every indicated day of water deficit stress treatment (Fig. 7A).

POD activity of $L$. aurea was higher than $L$. radiata under unstressed conditions (Fig. 7B). Although at the early stage of water deficit stress, the POD activity of $L$. aurea was greater than $L$. radiata. POD activities were $130 \%$ and $129 \%$ at day 4 , and $160 \%$ and $160 \%$ at day 8 as compared with their unstressed controls in L. aurea and $L$. radiata, respectively. Compared with $L$. radiata, the peak of POD activity in $L$. aurea displayed earlier, which appeared at day 8 with water deficit stress treatment. After $12 \mathrm{~d}$ of further water deficit stress, POD activity in $L$. aurea reached the maximum, while the POD activity in L. aurea began to decline. At the last stage of water deficit stress treatment, POD activities of $L$. radiata and $L$. aurea decreased, and there was even no difference detected between the unstressed control and the stressed sample in $L$. aurea (Fig. 7B).

When treated with water deficit stress, CAT activity of $L$. aurea obtained the maximum height at day 8 , whereas the maximum CAT activity of $L$. radiata displayed at day 
$16,24.47 \%$ and $34.82 \%$ greater than their unstressed controls, respectively. CAT activities in two species were still greater than their unstressed controls at day 12. However, L. aurea showed a moderate trend, and even after $16 \mathrm{~d}$ of water deficit stress, CAT activity of $L$. aurea reached almost the same value as the unstressed control (Fig. 7C).

Under water deficit stress, activities of APX in the two species showed a similar

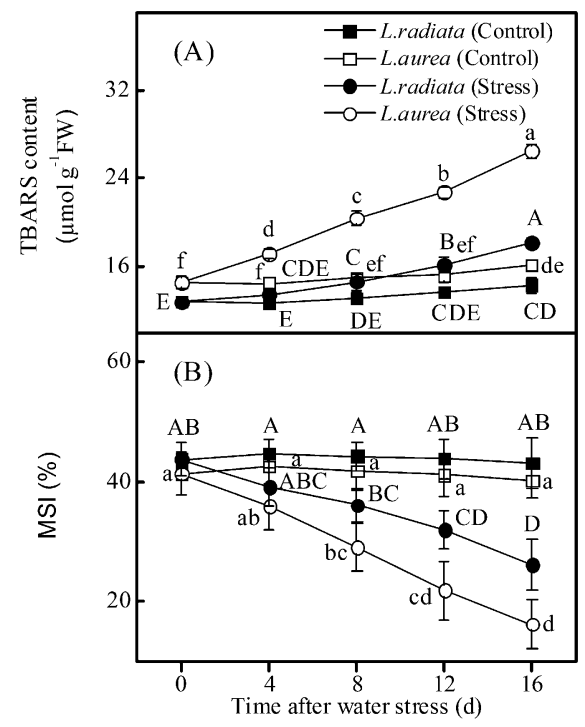

Fig. 6. (A) Thiobarbituric acid reactive substances (TBARS) content and (B) membrane stability index (MSI) changes in Lycoris radiata and Lycoris aurea as influenced by water deficit stress. Data are the means of three replicates with SDS shown by vertical bars. Data of each parameter within each species followed by the same letter are not significantly different $(P<0.05)$. trend, but the activity of $L$. radiata was significantly greater than that of $L$. aurea at each treatment time point. APX activities of the two species simultaneously achieved the maximum at day 12. Subsequently, APX activities of both species decreased and they were $153 \%$ and $109 \%$ of their unstressed controls at day 16, independently. It is obvious that APX activity of $L$. aurea declined more than that of L. radiata (Fig. 7D).

\section{Discussion}

High RWC is associated with water deficit stress resistance, and it also has been proposed as a more valuable indicator of plant status (Keles and Oncel, 2002). In this study, we showed that $L$. radiata maintained a relatively higher leaf RWC as compared with $L$. aurea (Fig. 1). This difference could be the cause of the higher tolerance to water deficit stress of $L$. radiata than $L$. aurea.

Decreased $P_{n}$ is due to stomatal and nonstomatal limitations (Flexas et al., 2006). Plants react to water deficit with a rapid closure of stomata to avoid further loss of water through transpiration, resulting in limitation of ambient $\mathrm{CO}_{2}$ diffusion to the mesophyll and thus reduction of photosynthesis (Flexas et al., 2006). It is suggested that the photosynthetic capacity of a plant was determined to large extent by its natural habitat and itself, and previous study has showed that $L$. radiata var. pumila and $L$. aurea were more adapted to a relatively high irradiance among four Lycoris species (Liu et al., 2012). Our results revealed a progressive reduction in the rate of $\mathrm{P}_{\mathrm{n}}$ and $g_{\mathrm{S}}$ in the two species. However, L. aurea showed a higher decrease in $\mathrm{P}_{\mathrm{n}}$ than $L$. radiata (Fig. 2A). Transpiration rate $(E)$ reduction

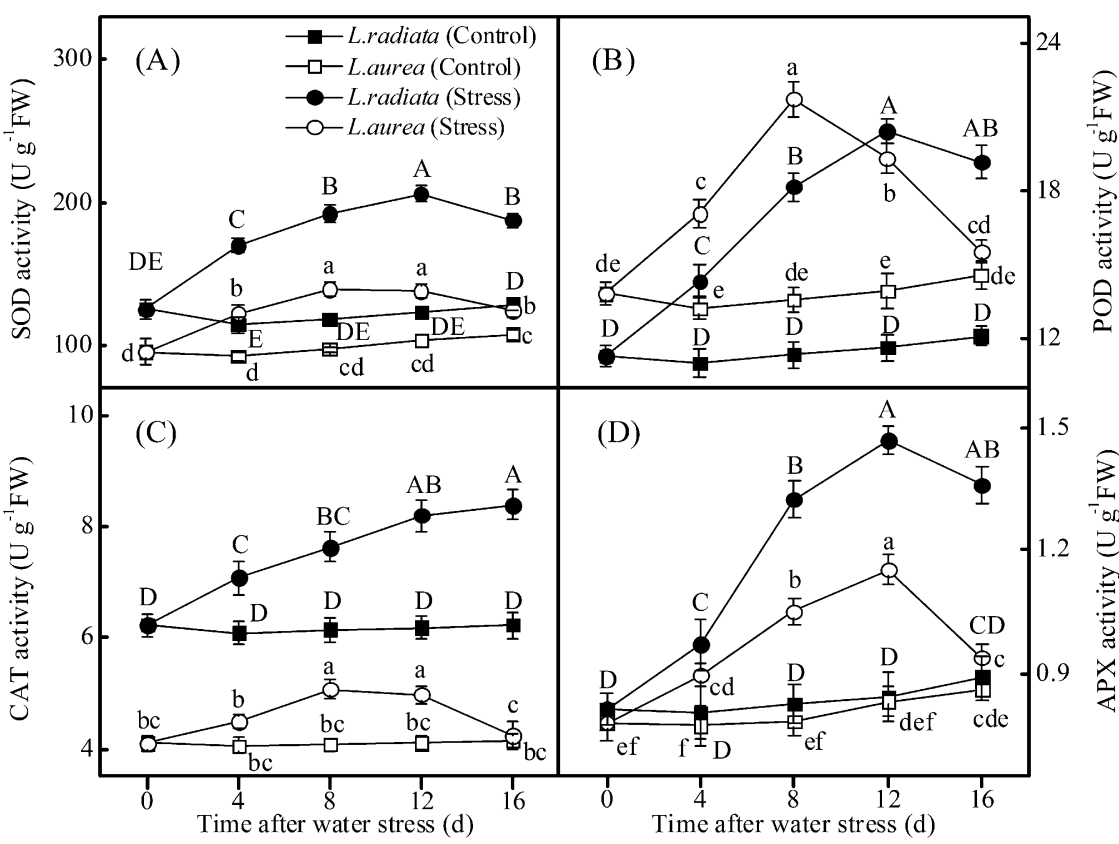

Fig. 7. (A) Superoxide dismutase (SOD), (B) guaiacol peroxidase (POD), (C) catalase (CAT), and (D) ascorbate peroxidase (APX) activity changes in Lycoris radiata and Lycoris aurea as influenced by water deficit stress. Data are the means of three replicates with sDs shown by vertical bars. Data of each parameter within each species followed by the same letter are not significantly different $(P<0.05)$. under water deficit stress is one of the plant responses for water maintenance. It has also been suggested that a major physiological reason for susceptibility differing between plant drought-susceptible and droughtresistant genotypes was the more efficient protection of tissue water status in resistant genotypes through greater decreases in $C_{\mathrm{i}}$, and thus in $E$, compared with susceptible genotypes (Grzesiak et al., 2006). Our results revealed higher decrease of gas exchange parameters $C_{\mathrm{i}}$ and $E$ on duration of water deficit stress for L. radiata in comparison with L. aurea (Fig. 2B and D). Maintaining $\mathrm{P}_{\mathrm{n}}$ under reduced $g_{\mathrm{S}}$ and $E$ in $L$. radiata during water deficit stress might lead to the increase in WUE (Fig. 2E). It has been stated that the WUE is critical to plant survival and crop yield. Higher WUE under drought stress is probably a consequence of gas exchange regulation. The $E$ parameter is more influenced by water deficit than $\mathrm{P}_{\mathrm{n}}$ in $L$. radiata and it had higher WUE during the water deficit stress period, which showed its ability to save water and uphold physiological activities under water deficit conditions. The present results are in agreement with findings reported previously (Bota et al., 2001; Gordon et al., 1999; Karimi et al., 2015; Zhang et al., 2004). In addition, correlations between $\mathrm{P}_{\mathrm{n}}$ and $g_{\mathrm{S}}$, and between $g_{\mathrm{S}}$ and $E$ were significantly linear and they were enhanced by water deficit stress (Fig. 3). Similar results were also observed previously (Sun et al., 2013). The relatively high AQY in low light indicates that shaded leaves have higher light-use efficiency, which is important for seedling establishment and growth (Zhang et al., 2007). In the current study, the values of LSP and AQY were higher in the leaves of $L$. radiata than those in $L$. aurea under water deficit stress (Table 1). In addition, $\mathrm{P}_{\mathrm{n}}$ increased with the increasing of PPFD in both species (Fig. 4).

Photosynthetic pigments are important to plants mainly for harvesting light and production of reducing powers. Water deficit stress can also alter the tissue concentrations of Chls and Cars (Farooq et al., 2009). Reduction of Chl contents under water deficit stress has been considered as a typical symptom of oxidative stress and may be the result of pigments of photooxidation and Chl degradation (Moran et al., 1994; Zhang and Kirkham, 1996). In addition, as photosynthetic pigments, Cars have the capacity to scavenge singlet oxygen and lipid peroxy radicals, as well as have the capacity to inhibit lipid peroxidation and superoxide generation under dehydrative forces (Havaux, 1998). The total Chl contents significantly decreased in both species under water deficit stress, but the reduction in $L$. radiata was not as great in $L$. aurea (Fig. 5A and $\mathrm{B}$ ). In addition, the ratio of Car to $\mathrm{Chl}$ increased first and then decreased in the two species under water deficit stress while $L$. radiata accumulated more Cars than $L$. aurea (Fig. 5C). These results suggested the presence of genetic variability for pigments retention between the two species under water stress deficit conditions. 
Increasing of proline amount due to water deficit stress has been reported previously (Mattioni et al., 1997). It is well known that proline, which accumulates in plants under dehydration and excessive osmotic pressure, contributes toward osmotic adjustment as key osmolyte (Yamada et al., 2005). This molecule acts not only as a protectant of the cell membrane and enzymes but also could provide energy for growth and survival under stress (Kavi Kishor et al., 2005). It was also shown that proline possesses antioxidant capacities (Szabados and Savouré, 2010). As we observed, proline accumulation in $L$. radiata during increasing water deficit was twice the amount found in L. aurea (Table 2), suggesting the better osmotic adjustment and better protection against reduced oxidative damage in L. radiata. As another organic osmolyte, soluble sugars (such as glucose and sucrose) can quench ROS, thus contributing to stress tolerance (Couée et al., 2006). Former study has showed that the soluble sugars increased significantly with water deficit stress (Khalid et al., 2010). In this study, both the Lycoris species accumulated soluble sugar under water deficit stress, whereas at the later stage of stress, the accumulating rate in $L$. radiata was faster than that in L. aurea (Table 2).

Water deficit stress also induces oxidative stress in plants by generation of ROS (Farooq et al., 2009). Drought-induced overproduction of ROS increases the content of TBARS. TBARS is the product of lipid peroxidation and its content has been considered an indicator of general oxidative damage (Møller et al., 2007). Low concentration of TBARS has been associated with water deficit stress tolerance in some plant species (Moran et al., 1994; Sharma and Dubey, 2005). Our results showed that the levels of TBARS in $L$. radiata were lower than $L$. aurea after water deficit stress, indicating the better protective mechanism of reduced oxidative damage in L. radiata. Moreover, a decrease in membrane stability also reflects the extent of lipid peroxidation. It is also suggested that the membrane disruption may alter water, ion, and organic solutes movement across the plant membrane, which interferes with photosynthesis and transpiration (Almeselmani et al., 2006). We noticed that L. radiata had a higher MSI than $L$. aurea under control as well as stress conditions at each treatment time (Fig. 6). This result indicated that lower MSI in L. aurea at water deficit stress stage was probably related to higher susceptibility to water loss.

In addition, the degree of damage caused by water deficit stress should be strongly dependent on the efficiency of activated protection and repair mechanisms, such as the antioxidant defenses, which have both enzyme and nonenzyme constituents (Møller et al., 2007). In this study, water deficit stress led to the increased production of ROS in two Lycoris species, which is reflected by the increase in the activities of antioxidant enzymes such as SOD, POD, CAT, and APX (Fig. 7). Within a cell, SOD constitutes the first line of defense against ROS (Ruth et al., 2002). It reacts with $\mathrm{O}_{2}^{-}$and converts them to $\mathrm{O}_{2}$ and $\mathrm{H}_{2} \mathrm{O}_{2}$. Water deficit stress also led to a relatively higher increase of SOD activity in $L$. radiata than in $L$. aurea, which meant that SOD activity also associates with the better protection against oxidative damage in $L$. radiata (Fig. 7A). CAT and POD play essential roles as scavengers in $\mathrm{H}_{2} \mathrm{O}_{2}$ toxicity (Foyer and Noctor, 2005). Several studies have provided evidence of an effective protector role of the POD-CAT-SOD system against oxidative stress in diverse plant species (Miller et al., 2010). APX is one of the components of the AsA-GSH cycle, which provides efficient protection against lethal ROS in all the subcellular organelles of plant cells (Møller et al., 2007). It was primarily located both in chloroplasts and cytosol acted as a key enzyme of the Asada-Halliwell pathway, which also eliminated toxic $\mathrm{H}_{2} \mathrm{O}_{2}$ (Foyer et al., 1994). In this study, the APX activities in $L$. radiata and $L$. aurea leaves were induced by water deficit stress and the activity of APX is much higher in L. radiata than in L. aurea (Fig. 7D). These results showing the variability in increasing the activities of these antioxidant enzymes between the two species indicates their differential ability to acquire water deficit stress tolerance.

In conclusion, water deficit stress affects many physiological and biochemical processes in the two Lycoris species, and we showed the varying responses and sensitivity to water deficit stress of them. Compared with $L$. aurea, $L$. radiata was more tolerant to water deficit stress as evidenced by its relatively higher water status, higher levels of proline, soluble sugar and pigments, and stronger photoprotection. Moreover, relatively higher antioxidant enzyme activities and lower levels of TBARS in L. radiata were also associated with its better protection against water deficit stress-induced oxidative damage.

\section{Literature Cited}

Almeselmani, M., P.S. Desmukh, R.K. Sairam, S.R. Kushwaha, and T.P. Singh. 2006. Protective role of antioxidant enzymes under high temperature stress. Plant Sci. 171:382-388.

Bates, L.S., R.P. Waldren, and I.D. Teare. 1973. Rapid determination of free proline for waterstress studies. Plant Soil 39:205-207.

Beauchamp, C. and I. Fridovich. 1971. Superoxide dismutase: Improved assays and an applicable to acrylamide gels. Anal. Biochem. 44:276287.

Bota, J., J. Flexas, and H. Medrano. 2001. Genetic variability of photosynthesis and water use in Balearic grapevine cultivars. Ann. Appl. Biol. 138:353-361.

Bradford, M.M. 1976. A rapid and sensitive method for the quantitation of microgram quantities of protein utilizing the principle of protein-dye binding. Anal. Biochem. 72:248-254

Chang, L., J. Chen, Y. Xiao, and Y. Xia. 2011. De novo characterization of Lycoris sprengeri transcriptome using Illumina GA II. Afr. J. Biotechnol. 10:12147-12155.

Couée, I., C. Sulmon, G. Gouesbet, and A. El Amrani. 2006. Involvement of soluble sugars in reactive oxygen species balance and responses to oxidative stress in plants. J. Expt. Bot. 57:449-459.

Deshmukh, P.S., R.K. Sairam, and D.K. Shukla. 1991. Measurement of ion leakage as a screening technique for drought resistance in wheat genotypes. Indian J. Plant Physiol. 34:89-91.

Farooq, M., A. Wahid, N. Kobayashi, D. Fujita, and S.M.A. Basra. 2009. Plant drought stress: Effects, mechanisms and management. Agron. Sustain. Dev. 29:185-212.

Flexas, J., M. Ribas-Carbó, J. Bota, J. Galmés, M. Henkle, S. Martinez-Cañellas, and H. Medrano. 2006. Decreased Rubisco activity during water stress is not induced by decreased relative water content but related to conditions of low stomatal conductance and chloroplast $\mathrm{CO}_{2}$ concentration. New Phytol. 172:73-82.

Foyer, C.H., M. Lelandais, and K.J. Kunert. 1994. Photooxidative stress in plants. Physiol. Plant. 92:696-717.

Foyer, C.H. and G. Noctor. 2005. Oxidant and antioxidant signalling in plants: A reevaluation of the concept of oxidative stress in a physiological context. Plant Cell Environ. 28:1056-1071.

Gordon, C., S.J. Woodin, C.E. Mullins, and I.J. Alexander. 1999. Effects of environmental change, including drought, on water use by competing Calluna vulgaris (heather) and Pteridium aquilinum (bracken). Funct. Ecol. 13:96-106

Grzesiak, M.T., S. Grzesiak, and A. Skoczowski. 2006. Changes of leaf water potential and gas exchange during and after drought in triticale and maize genotypes differing in drought tolerance. Photosynthetica 44:561-568.

Havaux, M. 1998. Carotenoids as membrane stabilizers in chloroplasts. Trends Plant Sci. 3:147-151.

He, Q., Y. Shen, M. Wang, M. Huang, R. Yang, S. Zhu, L. Wang, Y. Xu, and R. Wu. 2011. Natural variation in petal color in Lycoris longituba revealed by anthocyanin components. PLoS One 6:e22098.

He, Q.L., S.J. Cui, J.L. Gu, H. Zhang, M.X. Wang, Y. Zhou, L. Zhang, and M.R. Huang. 2010. Analysis of floral transcription factors from Lycoris longituba. Genomics 96:119-127.

Herzog, V. and H. Fahimi. 1973. A new sensitive colorimetric assay for peroxidase using $3,3^{\prime}$-diaminobenzidine as hydrogen donor. Anal. Biochem. 55:554-562.

Hodges, D.M., J.M. DeLong, C.F. Forney, and R.K. Prange. 1999. Improving the thiobarbituric acid-reactive-substances assay for estimating lipid peroxidation in plant tissues containing anthocyanin and other interfering compounds. Planta 207:604-611.

Hsu, P.S., K. Siro, Z.Z. Yu, and J.Z. Lin. 1994 Synopsis of the genus Lycoris (Amaryllidaceae). SIDA 16:301-331.

Karimi, S., A. Yadollahi, K. Arzani, A. Imani, and M. Aghaalikhani. 2015. Gas-exchange response of almond genotypes to water stress. Photosynthetica 53:29-34.

Kavi Kishor, P.B., S. Sangam, R.N. Amrutha, P.S Laxmi, K.R. Naidu, K.R.S.S. Rao, S. Rao, K.J. Reddy, P. Theriappan, and N. Sreenivasulu. 2005. Regulation of proline biosynthesis, degradation, uptake and transport in higher plants: Its implications in plant growth and abiotic stress tolerance. Curr. Sci. 88:424-438.

Keles, Y. and I. Oncel. 2002. Response of antioxidative defence system to temperature and water stress combinations in wheat seedlings. Plant Sci. 163:783-790.

Khalid, K.A., J.A. Teixeira da Silva, and W. Cai. 2010. Water deficit and polyethylene glycol 6000 affects morphological and biochemical 
characters of Pelargonium odoratissimum (L.). Sci. Hort. 125:159-166.

Lichtenthaler, H.K. 1987. Chlorophylls and carotenoids: Pigments of photosynthetic biomembranes. Methods Enzymol. 148:350-382.

Liu, K., C.F. Tang, S.B. Zhou, Y.P. Wang, D. Zhang, W.D. Wu, and L.L. Chang. 2012. Comparison of the photosynthetic characteristics of four Lycoris species with leaf appearing in autumn under field conditions. Photosynthetica 50:570-576.

Mattioni, C., N.G. Lacerenza, A. Troccoli, A.M De Leonardis, and N. Di Fonzo. 1997. Water and salt stress-induced alterations in proline metabolism of Triticum durum seedlings. Physiol. Plant. 101:787-792.

Meng, P., Y. Ge, Q. Cao, J. Chang, P. Pan, and C. Liu. 2008. Growth and photosynthetic responses of three Lycoris species to levels of irradiance. HortScience 43:134-137.

Miller, G., N. Suzuki, S. Ciftci-Yilmaz, and R. Mittler. 2010. Reactive oxygen species homeostasis and signalling during drought and salinity stresses. Plant Cell Environ. 33:453-467.

Moran, J.F., M. Becana, I. Iturbe-Ormaetxe, S. Frechilla, R.V. Klucas, and P. Aparicio-Tejo. 1994. Drought induces oxidative stress in pea plants. Planta 194:346-352.

Møller, I.M., P.E. Jensen, and A. Hansson. 2007. Oxidative modifications to cellular components in plants. Annu. Rev. Plant Biol. 58:459-481.

Nakano, Y. and K. Asada. 1981. Hydrogen peroxide is scavenged by ascorbate-specific peroxidase in spinach chloroplasts. Plant Cell Physiol. 22:867-880.

Ruth, G.A., E. Neval, and S.H. Lenwood. 2002. Role of superoxide dismutases (SODs) in controlling oxidative stress in plants. J. Expt. Bot. 53:1331-1341.

Sharma, P. and R.S. Dubey. 2005. Drought induces oxidative stress and enhances the activities of antioxidant enzymes in growing rice seedlings. Plant Growth Regulat. 46:209-221.

Shrestha, M.K., W.D. Stock, D. Ward, and A. GolanGoldhirsh. 2003. Water status of isolated Negev desert populations of Acacia raddiana with different mortality levels. Plant Ecol. 168:297-307.

Sun, X.P., H.L. Yan, X.Y. Kang, and F.W. Ma. 2013 Growth, gas exchange, and water-use efficiency response of two young apple cultivars to drought stress in two scion-one rootstock grafting system. Photosynthetica 51:404-410.

Szabados, L. and A. Savouré. 2010. Proline: A multifunctional amino acid. Trends Plant Sci. 15:89-97.

Tezara, W., V.J. Mitchell, S.D. Driscoll, and D.W Lawlor. 1999. Water stress inhibits plant photosynthesis by decreasing coupling factor and ATP. Nature 401:914-917.

Toriizuka, Y., E. Kinoshita, N. Koqure, M. Kitajima, A. Ishiyama, K. Otoquro, H. Yamada, S. Omura, and H. Takayama. 2008. New lycorine-type alkaloid from Lycoris traubii and evaluation of antitrypanosomal and antimalarial activities of lycorine derivatives. Bioorg. Med. Chem. 16:10182-10189.
Wang, R., S. Xu, Y. Jiang, J. Jiang, X. Li, L. Liang, J. He, F. Peng, and B. Xia. 2013. De novo sequence assembly and characterization of Lycoris aurea transcriptome using GS FLX titanium platform of 454 pyrosequencing. PLoS One 8:e60449.

Yamada, M., H. Morishita, K. Urano, N. Shiozaki, K. Yamaquchi-Shinozaki, K. Shinozaki, and Y. Yoshiba. 2005. Effects of free proline accumulation in petunias under drought stress. J. Expt. Bot. 56:1975-1981.

Yemm, E.W. and A.J. Willis. 1954. The estimation of carbohydrates in plant extracts by anthrone. Biochem. J. 57:508-514.

Zhang, J. and M.B. Kirkham. 1996. Antioxidant responses to drought in sunflower and sorghum seedlings. New Phytol. 132:361-373.

Zhang, S.B., H. Hu, K. Xu, Z.R. Li, and Y.P. Yang. 2007. Flexible and reversible responses to different irradiance levels during photosynthetic acclimation of Cypripedium guttatum. J. Plant Physiol. 164:611-620.

Zhang, X., R. Zang, and C. Li. 2004. Population differences in physiological and morphological adaptations of Populus davidiana seedlings in response to progressive drought stress. Plant Sci. 166:791-797.

Zhou, S.B., B.Q. Yu, Q. Luo, J.R. Hu, and D. Bi. 2007. Karyotypes of six populations of Lycoris radiata and discovery of the tetraploid. Acta Phytotaxon. Sin. 45:513-522.

Zhu, J.K. 2002. Salt and drought stress signal transduction in plants. Annu. Rev. Plant Biol. 53:247-273. 